\title{
Existe Relaçáo Entre Sobrecarga do Cuidador, Perfil Funcional e Qualidade de Vida na Paralisia Cerebral?
}

\author{
Alba Barros Souza Fernandes \\ Fisioterapeuta, Doutora em Ciências, Professora Adjunta dos Cursos de Graduaçáo em Fisioterapia e Medicina do \\ Centro Universitário Serra dos Órgãos (UNIFESO), Rio de Janeiro-RJ, Brasil.
}

A paralisia cerebral (PC) apresenta alta incidência, podendo apresentar vários níveis de gravidade e diversas complicaçóes. O nascimento de uma criança com paralisia cerebral gera uma série de reaçóes emocionais e de adaptaçóes psicossociais, que podem diminuir a qualidade de vida do cuidador ${ }^{1,2}$, que é aquela pessoa responsável pelo cuidado direto e diário da criança, podendo ser mãe, pai, avó, ou qualquer outra pessoa que exerça esse papel ${ }^{3,4}$.

A presença de doenças crônicas não altera somente a vida dos indivíduos acometidos, mas também pode influenciar de diferentes formas os cuidadores ${ }^{5}$, visto que a saúde psicológica e física pode ser fortemente influenciada pelo comportamento da criança e pela demanda de cuidado. Dessa forma, o cuidador primário da criança com PC, que normalmente é a mãe, altera sua vida em função de melhorar a condição da criança e passa a não desenvolver seus próprios papéis sociais 5 . Por essas razóes, as mães das crianças com PC poderão, comparativamente às mães de crianças sem deficiência, apresentar risco mais elevado de apresentar variaçôes no nível da saúde mental e do bem-estar psicológico ${ }^{3}$.

Neste número da Revista Neurociências, no artigo "Relação da Sobrecarga do Cuidador, Perfil Funcional e Qualidade de Vida em Crianças com Paralisia Cerebral"', os autores se propuseram a analisar a influência do comprometimento motor na qualidade de vida de crianças com diagnóstico de PC e a sobrecarga de seus cuidadores.

Nesse estudo, foram incluídas 12 crianças com PC, com idades entre cinco a 12 anos, sendo seis quadriplégicos e seis diplégicos, com cognição preservada para compreensão de ordens simples, bem como seus respectivos cuidadores.

As crianças foram avaliadas com relação à qualida- de de vida, através do questionário Avaliação de Qualidade de Vida (AUQEI), que, segundo os autores, trata-se de uma escala validada, de total confiabilidade e de fácil aplicação em crianças de quatro a 12 anos, assim como com relação ao nível de funcionalidade, através do Gross Motor Function Classification System (GMFCS), que é um sistema que tem a finalidade de fornecer uma classificação objetiva dos padróes de incapacidade motora ${ }^{2}$. O GMFCS é um sistema de classificação da função motora ampla, e a gravidade do comprometimento neuromotor é descrita, principalmente, na forma da locomoção utilizada ${ }^{3}$.

Já os cuidadores foram avaliados em relação à sobrecarga, através da versão brasileira da Burden Interview, que contém perguntas englobando as áreas de saúde, vida social e pessoal, situação financeira, bem-estar emocional e relacionamento interpessoal. Essa escala pode ser utilizada para avaliar a sobrecarga dos cuidadores de indivíduos com incapacidades mental e física, e foi recentemente traduzida e validada para a população brasileira 5 .

Os resultados do estudo mostraram que a maioria das crianças apresentou nível IV de funcionalidade e qualidade de vida média. Além disso, foi observada correlação entre o tipo clínico de PC e o grau de funcionalidade e entre este e a qualidade de vida das crianças. Não houve correlação entre o tipo clínico e a qualidade de vida das crianças. Também não foi evidenciado sobrecarga do cuidador, mas sim, uma qualidade de vida satisfatória.

A literatura é controversa em relação à qualidade de vida de cuidadores de crianças com PC. Alguns estudos verificaram indisposição para a realização de atividades físicas, para o relacionamento social, má percepção da saúde, predisposição ao estresse, falta de conhecimento a respeito da doença do filho, diminuição do humor 
e problemas no convívio social, familiar e profissional, mostrando que o comprometimento motor da criança interfere na percepção da qualidade de vida materna ${ }^{4,5}$.

Estudos demonstraram que os cuidadores de crianças com PC com nível socioeconômico elevado controlam melhor o seu bem-estar quando comparados com cuidadores com nível socioeconômico inferior. Um terço das mães de crianças com doenças crônicas necessitam parar de trabalhar para cuidar de seus filhos que estão em tratamento. Além disso, cuidar de uma criança com incapacidade aumenta a demanda de recursos, o que pode aumentar a sobrecarga dos cuidadores, quando esses são membros economicamente ativos da família 5 . Entretanto, os resultados do presente estudo não foram correlacionados com o perfil socioeconômico desses indivíduos, apesar de influenciar na avaliação da sobrecarga do cuidador avaliada pelo Burden Interview.

Normalmente, a sobrecarga dos cuidadores de crianças com comprometimentos motores mais leves é maior do que a de crianças mais graves, mas este fato não foi observado neste estudo, visto que a avaliação não mostrou presença de sobrecarga dos cuidadores, independentemente do grau de comprometimento da criança.

Nem todos os estudos mostram que o grau de incapacidade funcional está associado à percepção negativa da qualidade de vida. Quando as máes tem um bom relacionamento e apoio familiar, elas se apresentam mais disponíveis e com menor sobrecarga emocional, independente do grau de comprometimento motor da criança ${ }^{2,4}$. Além disso, a ausência de sobrecarga desses cuidadores pode ser pelo fato das crianças estarem em tratamento fisioterapêutico em um centro especializado. $\mathrm{O}$ suporte social dado por essas instituições é importante para auxiliar a família a enfrentar a situação de uma forma mais tranquila. Assim, o convívio com outras famílias que enfrentam o mesmo problema ajuda a diminuir o sofri- mento e a sensação de abandono ${ }^{5}$. No presente estudo, provavelmente os cuidadores são familiares diretos, principalmente mãe, o que corrobora esta hipótese.

Devido ao caráter multifatorial que influencia a qualidade de vida de um indivíduo, o nível de prejuízo na qualidade de vida das famílias de crianças com condiçóes crônicas graves pode ser influenciado por vários fatores ${ }^{1,3}$. Portanto, é necessário conhecer profundamente todos os aspectos biopsicossociais em que os mesmos estão inseridos, visando à compreensão do paciente e da repercussão da doença no contexto familiar. Com uma intervenção mais contextualizada, é possível a prestação de uma assistência de melhor qualidade. Conhecendo melhor todos os aspectos da vida dessas cuidadores, os profissionais da saúde poderão atuar não só no comprometimento físico da criança, mas em toda a rotina familiar.

\section{REFERÊNCIAS}

1.Prudente COM, Barbosa MA, Porto CC. Relação entre a qualidade de vida de mães de crianças com paralisia cerebral e a função motora dos filhos, após dez meses de reabilitação. Rev Latino-Am Enfermagem 2010;18(2):3-8.

2.Carvalho JTM, Rodrigues NM, Silva LVC, Oliveira DA. Qualidade de vida das mães de crianças e adolescentes com paralisia cerebral. Fisioter Mov 2010;23(3):389-97.

\section{http://dx.doi.org/10.1590/S0103-51502010000300006}

3.Rocha AP, Afonso DRV, Morais RLS. Relação entre desempenho funcional de crianças com paralisia cerebral e qualidade de vida relacionada à saúde de seus cuidadores. Fisioter Pesq 2008;15(3):292-7.

4.Camargos ACR, Lacerda TTB, Barros TV, Silva GC, Parreiras JT, Vidal THJ. Relação entre independência funcional e qualidade de vida na paralisia cerebral. Fisioter Mov 2012;25(1):83-92.

5.Camargos ACR, Lacerda TTB, Viana SO, Pinto LRA, Fonseca MLS. Avaliação da sobrecarga do cuidador de crianças com paralisia cerebral através da escala Burden Interview. Saude Mater Infant 2009;9(1):31-7.

http://dx.doi.org/10.1590/S1519-38292009000100004

6.Barbosa APM, Zampa TN, Iwabe C, Diz MAR. Relação da Sobrecarga do Cuidador, Perfil Funcional e Qualidade de Vida em Crianças com Paralisia Cerebral. Rev Neurocienc 2012;20(3):367-71. 